\title{
Performance Investigation of MEMSYS Vacuum Membrane Distillation System in Single Effect and Multi-Effect Mode
}

\author{
Muhammad Burhan $^{1 *}$, Muhammad Wakil Shahzad ${ }^{2}$, Doskhan Ybyraiymkul ${ }^{3}$, \\ Seung Jin $\mathrm{Oh}^{4}$, Noreddine Ghaffour ${ }^{5}$ and Kim Choon $\mathrm{Ng}^{6}$ \\ ${ }^{1-6}$ Water Desalination and Reuse Center, Biological and Environmental Science and Engineering \\ Division, King Abdullah University of Science and Technology, Saudi Arabia. \\ *Corresponding author: muhammad.burhan@kaust.edu.sa
}

\begin{abstract}
:
With increase in fresh water demand and lack of fresh water resources, the current water scarcity can only be solved with seawater desalination. However, due to high dependence of current desalination technologies on fossil fuels, especially in GCC countries where the share of thermal desalination systems is dominating, the environmental sustainability is at risk. Despite high operational and maintenance cost, electricity operated membrane based reverse osmosis (RO) system provides simple configuration with less capital cost. Therefore, for future sustainable desalination, more innovative and energy efficient methods have to be sought out which will not only have the low operational cost of the thermal desalination systems but they can also have simple design and fabrication cost of membrane based systems. Vacuum membrane distillation (VMD) is a thermal distillation technique that works on the vapor pressure across the hydrophobic membrane. With the introduction of heat recovery scheme within the VMD modules in form of the multi-effect VMD operation, a detailed performance analysis of the VMD system is presented in this study under different operating conditions.. The performance of system is investigated on components level with comparison between single effect and multi-effect operation.
\end{abstract}

Keywords: Membrane Distillation, Desalination, Sustainable, Membrane, MEMSYS

\section{Introduction}

Water scarcity is becoming a serious global issue. It is estimated that by 2050 , the global demand of fresh water will be increased by 55\%. This high demand is due to increase in population and gross domestic product (GDP). In such scenario, the desalination of seawater which is covering almost $71 \%$ of the earth's surface, can provide the practical solution to meet the global water demand, especially in the GCC countries which have almost negligible fresh water availability [15]. These countries are planning to ramp up their current desalination plants to several folds to meet the ever increasing water demand. In Saudi Arabia, most of these desalination plants are thermally operated systems which can consume more than 300,000 barrels of oil, to meet the daily water demand [6-10]. With increased environmental problems and increasing water supply demand gap, there is a need to have efficient and sustainable desalination systems. 
In current global warming situation where all of the efforts are being made to limit the global temperature rise to $1.5^{\circ}$, it seems difficult to achieve the set targets under such extensive use of fossil fuels [11-15]. The use of renewable energy resources as primary energy supply is considered to be a sustainable solution for current environmental problems. However, their intermittency and low power density can be seen as the main reason for their sluggish implementation [16-19]. On the other hand, high energy density and ready availability of fossil fuels make them superior over renewable energy resources, for current energy extensive desalination systems [20-22]. Therefore, more innovative desalination methods are needed to be explored to operate with sustainable energy sources like solar [23-25].

Moreover, the conventional design of thermal based desalination systems offers very high capital cost of US $\$ 2000 / \mathrm{m}^{3}$, like MED (multi-effect desalination, water cost: $0.52-8.0 \mathrm{US} \$ / \mathrm{m}^{3}$ ) and MSF (multi-stage flashing) [26-28] as the manufacturers of such systems are packing the evaporators and condensers with high tube density, to increase the overall heat transfer area for high thermal performance, resulting in higher fabrication cost. Such complex design also leads to high maintenance and are susceptible to corrosion and fouling, due to inaccessibility between the surfaces of such highly packed tubes [29-31]. On the other hand, these thermal systems provide a low operational cost as compared to the pressure driven membrane based reverse osmosis (RO) system. The RO systems require high grade electrical energy and depend upon feed conditions which can lead to plant shutdown in case of hazardous algae blooms (HAB) e.g. along the golf in year 2008 and 2013. For future sustainable desalination, more innovative and energy efficient methods have to be sought out which can have the advantage of simple operation of thermal systems but they can also have simple configuration of membrane based systems $[32,33]$.

Vacuum membrane distillation is a thermal distillation technique that works on the vapor pressure across the hydrophobic membrane. On one side of the membrane, the higher vapor pressure is achieved by high temperature of feed water. However, on other side, the lower vapor pressure is achieved through vacuum. So, with vacuum driven membrane distillation (MD), we can achieve higher vapor pressure difference across membrane and low vapor flow resistance, unlike conventional membrane distillation techniques. In this paper, a detailed design and performance investigation of MEMSYS (Memsys Water Technologies GmbH, Germany) vacuum membrane distillation system (VMD) is discussed. The MEMSYS is a company which has specific configuration of VMD with heat recovery between different effects or stages. The analysis of this technology is presented on small lab scale pilot in single effect and multi-effect mode.

\section{Vacuum Membrane Distillation (VMD) Testing Facility}

The overall layout and the component details of vacuum driven membrane distillation setup is shown in Fig. 1. From the shown system layout, it can be seen that the heart of the system is VMD modules assembly which is connected to steam riser and condenser at each side. There are total 4 VMD modules which are connected in series. The steam riser is connected to hot water tank which is supplying heat to the incoming feed through hot water circulation. The hot water tanks must 
keep a certain level of hot water storage for steady and safe operation, which is maintained by the fresh makeup water supply to the system. The distillate produced from the first stage is collected into a small tank and supplied back to the hot water storage tank to have less makeup water requirements.

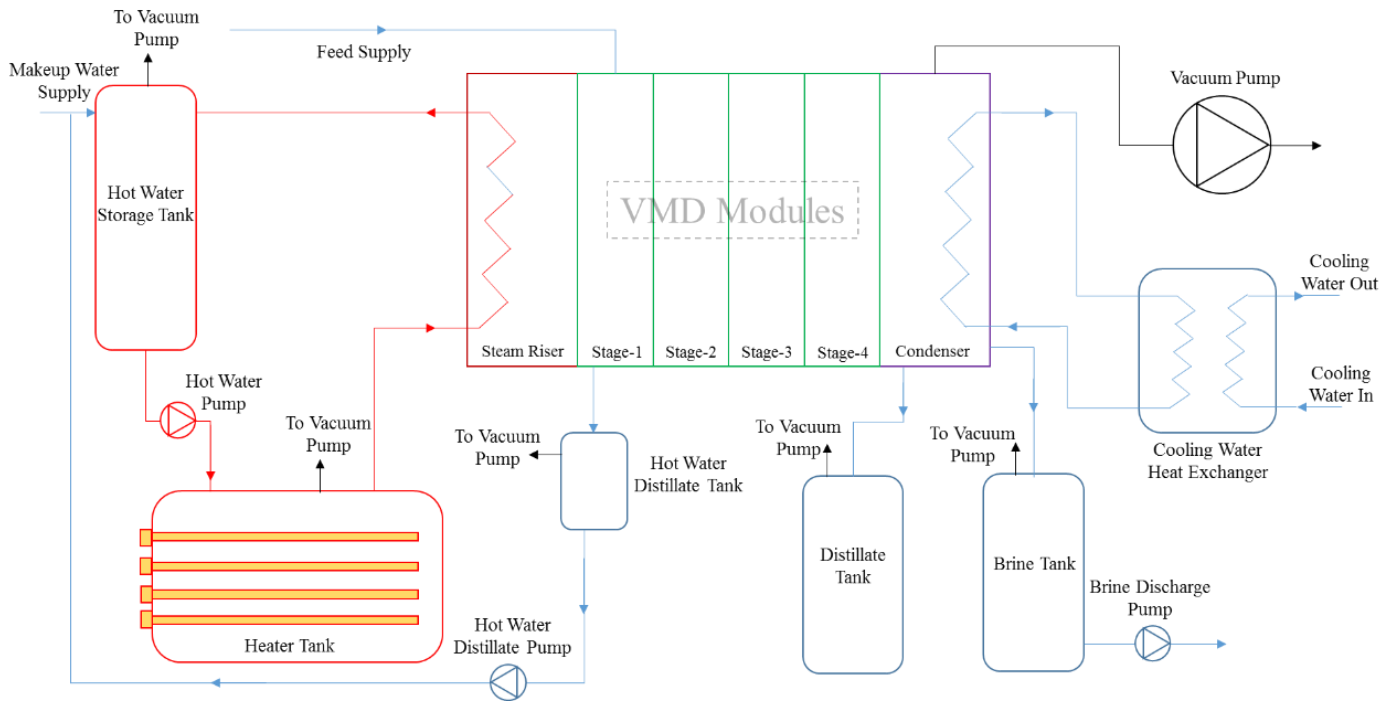

(a)

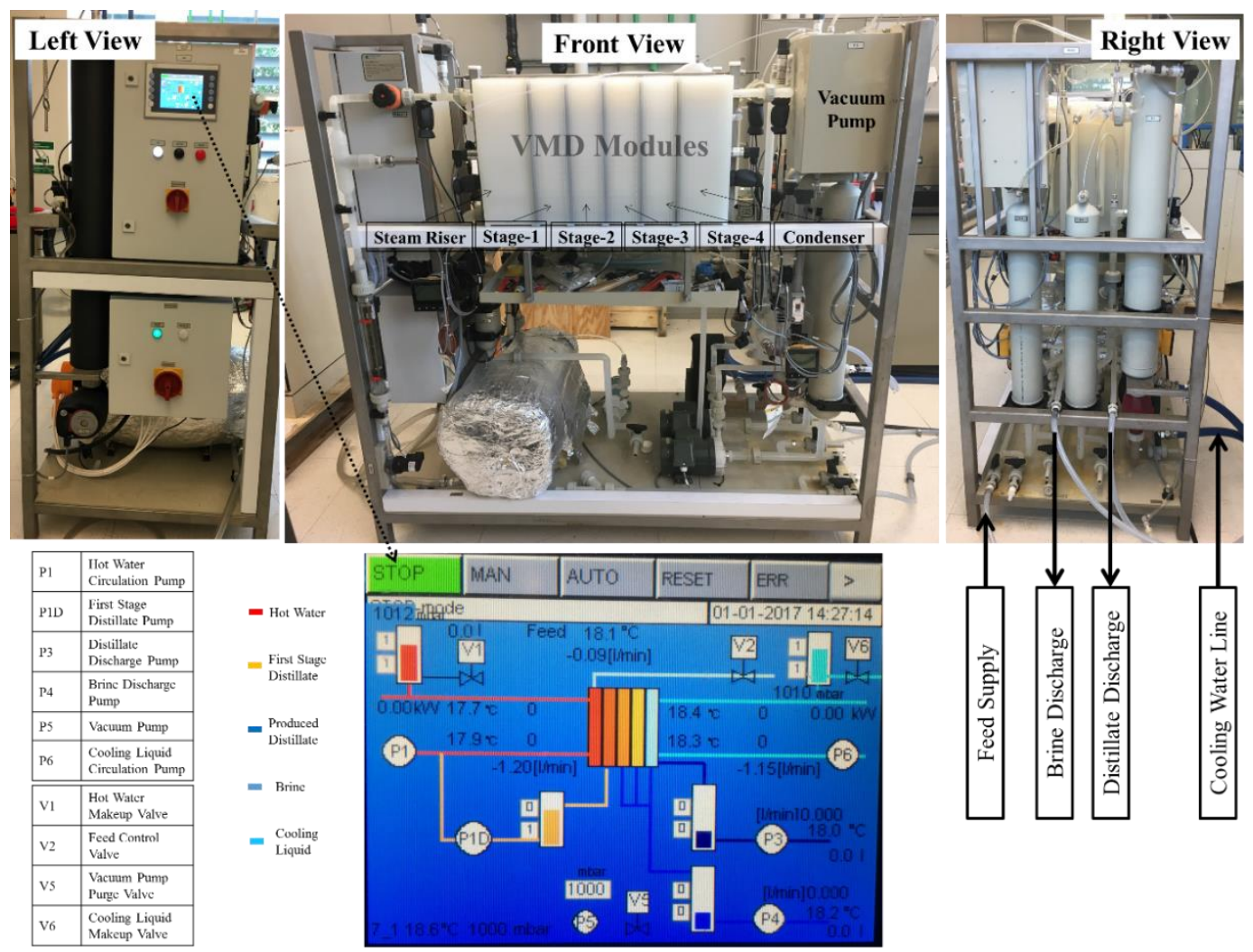

(b)

Figure 1: Vacuum Membrane Distillation (VMD) System (a) Layout (b) Experimental Setup 
The other end of the VMD modules assembly is connected to the condenser. The cooling circuit is working in two stage; the cooling media flowing through the condenser operates in a closed loop and rejects its heat to the chilled water in a heat exchanger. The brine and distillate are collected into their respected tanks where they can be drained through discharge pumps. The entire system is operating under vacuum, through vacuum pump which is not only connected to the VMD modules and their respective steam riser and condenser, but also to the storage tanks and heaters, to ensure proper fluid flow in the system.

Figure 1(b) shows the experimental test rig of vacuum membrane distillation (VMD) system from MEMSYS. The feed supply line is connected to the fresh water line. However, the distillate discharge is connected to an external water storage tank whose weight is measured during the experiment. However, the brine discharge line is connected to the drain and the cooling water is supplied through chilled water supply line. The overall operation of the system is managed through PLC control. All of the storage tanks are connected to level sensors which can automate the system against high and low liquid levels in the tank. The required temperature and pressure sensors are connected at different points in each of the system component, to analyze its performance. The performance data is logged automatically by the PLC control.

\subsection{VMD Module Configuration and Assembly}

Figure 2 shows the design arrangement of the single VMD module. It is made-up of multiple membrane frames which are connected in a certain pattern to have proper flow of each of the system fluid. In the VMD module, one of the frame contains PTFE membrane, acting as the hydrophobic membrane, and the other frame contains the PP foil that acts as the separator as no liquid or vapor can pass through it except heat. The frames have a certain arrangement of holes which are either blocked or opened, depending upon the membrane or PP foil application, when they are assembled together. The left side of Fig. 2 shows the design assembly of the VMD module and the right side of the Fig. 2 shows the assembled single VMD module. The black line on the module is presenting O-rings which are attached to the modules for proper vacuum tight seal when VMD modules are joined together to work as a system.

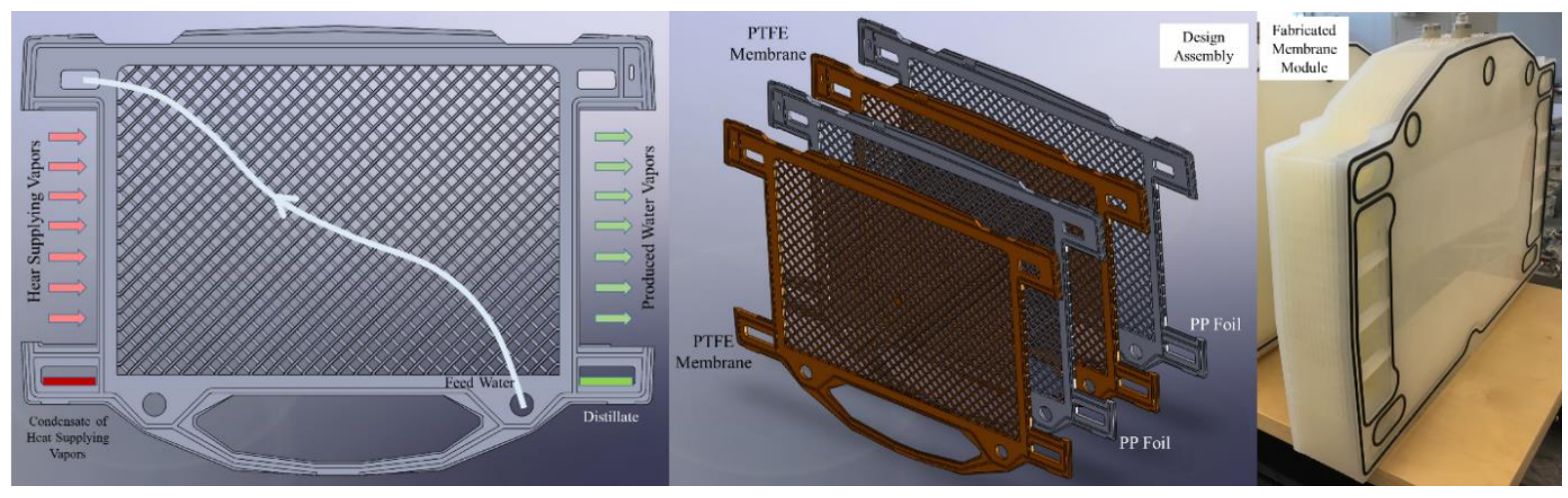

Figure 2: Design Assembly and Fabrication of VMD Module 
From the design of single frame, it can be seen that the perforated area in the center is to support the MD membrane or PP foil. In order to have better heat and mass transfer, feed and vapors have counter flow. In addition, there is also cross flow of feed across the membrane or PP foil, to have uniform distribution of liquid over the entire contact area and to make sure the MD module is filled with the feed water. The MD frame has holes at the each side, for the vapors to enter and to leave. There are also separate channels at the bottom sides, for the flow of condensate or distillate. The frame is designed such that each fluid stream has its own flow path and they does not mix with each other. Depending upon the flow arrangement, these holes can be closed and opened as per requirement of single effect and multi-effect configurations. The detailed flow schematic of VMD module, Fig, 2, is shown in Fig. 3 which represents the assembly and corresponding flow of each fluid when VMD modules are arranged in single and multiple effect modes.

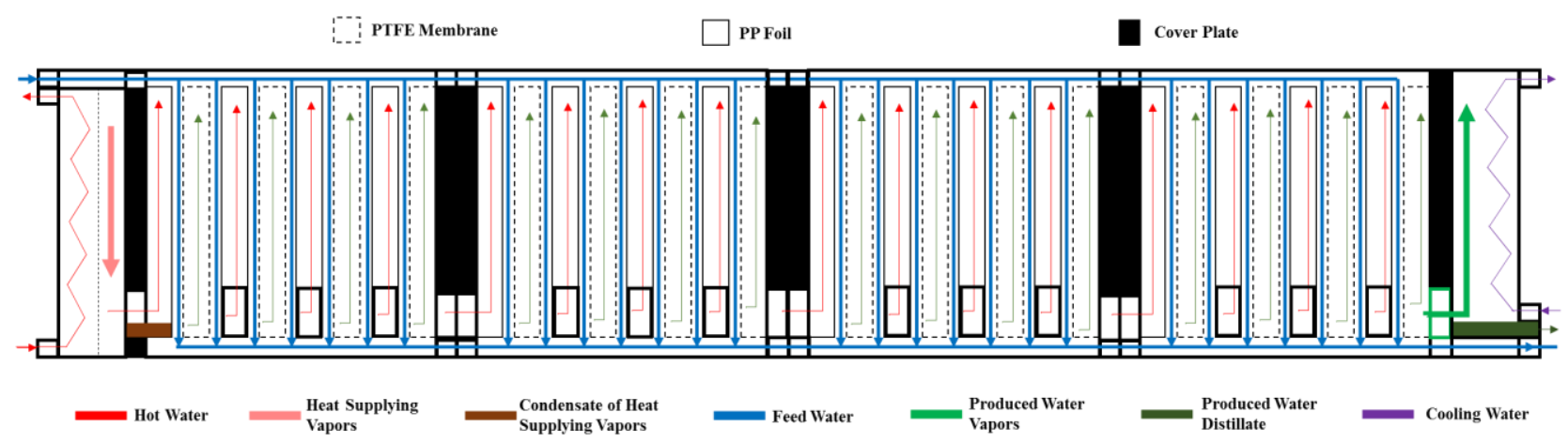

(a)

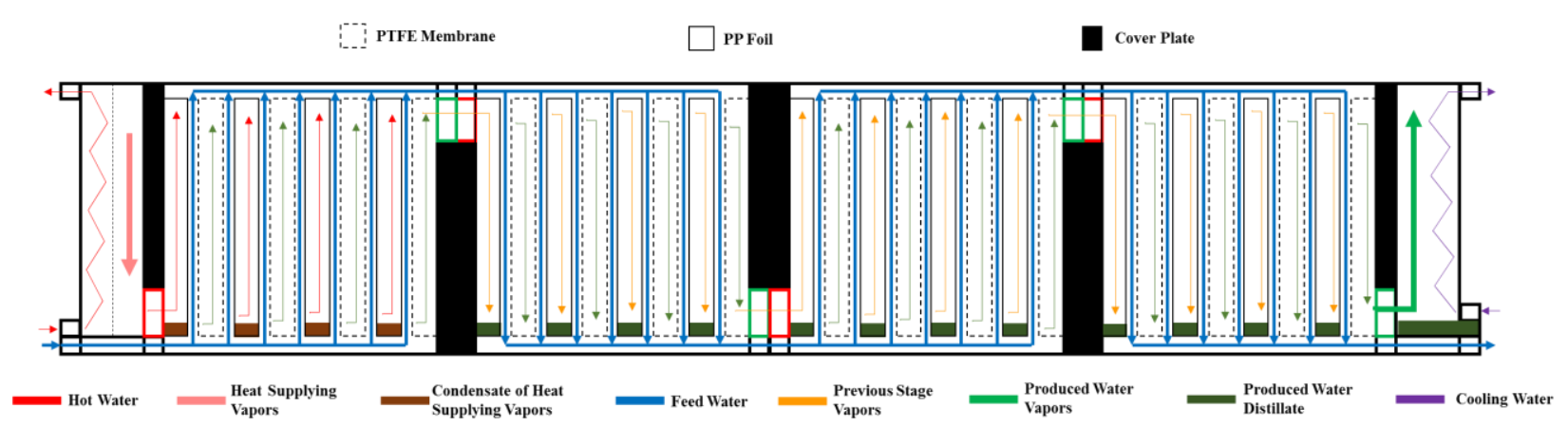

(b)

Figure 3: Schematic of VMD System with Fluid Flows (a) Single Effect (b) Multi-Effect

\subsubsection{Single effect configuration}

Figure 3(a) shows the schematic of fluid flows through single effect 4-stage VMD system. Each VMD module, as shown in Fig. 2, represents one stage that can have multiple arrangement of MD membrane and PP foil frames. This arrangement, as shown in Fig. 3(a), is called as parallel feed arrangement or single effect system in which feed enters to each modules at the same condition. The heat supply to the feed comes from the heat supplying vapors which are generated through hot water flow from steam riser. Steam riser is also a kind of VMD modules which have 
hydrophobic PTFE membrane. Hot water flows at one side of the membrane and due to vacuum on the other side, there is a vapor pressure difference that generates the vapors but at higher temperature. These hot vapors are further utilized to supply heat to the incoming feed for MD process. The arrangement of MD frame is kept such that the feed flow has heat supplying vapors on one side, separated by PP foil, and the produced vapors on the other side, separated by the hydrophobic PTFE membrane. The hot vapors reject their heat to feed, which raises feed temperature or vapor pressure difference across the membrane, resulting in vapor flow through the membrane. During feed heating process, the hot vapors condenses and are returned back to the hot water tank. However, the produced vapors enter into the condenser, where they are condensed through cold water circulation.

\subsubsection{Multi-effect configuration}

Figure 3(b) shows the design arrangement of the multi-effect VMD modules. This assembly has feed supply in series in which feed enters from one module to another, with heat recovery from the condensate of previous stage. On the other hand, the arrangement of feed in the single effect mode was parallel, where feed enters in each layer with same condition. In multi-effect mode, the vapors produced from $1^{\text {st }}$ stage enter into the $2^{\text {nd }}$ stage, where they condense by exchanging heat to the feed flow of $2^{\text {nd }}$ stage. The process continues till stage 4 where there is not much energy to be recovered and the produced vapors are sent to the condenser.

\section{Results and Discussion}

In this section, first of all, the performance of the VMD system, as single effect and multi-effect, will be analyzed in terms of its temperature profile, pressure profile, and flow-rate and power profile at certain hot water temperature. After that, the system output in terms of total distillate production and recovery ratio, for different heat source temperatures, will be presented and discussed.

Figure 4(a) shows the temperature profile of different components of the VMD system under single effect operation, with hot water set inlet temperature of $50^{\circ} \mathrm{C}$ which is the maximum temperature capacity of current VMD system under single effect operation. The feed inlet temperature was $23^{\circ} \mathrm{C}$, same as the fresh water supply line available in the lab, and the cooling water inlet temperature was $16^{\circ} \mathrm{C}$, also same as the chilled water supply line temperature in the lab. From the temperature profile, it can be seen that although, the hot water inlet temperature was set at $50^{\circ} \mathrm{C}$, but the system could only reach and maintain maximum temperature of $49^{\circ} \mathrm{C}$. However, the hot water outlet temperature is steady at $42^{\circ} \mathrm{C}$. Therefore, a temperature difference of $7^{\circ} \mathrm{C}$ was maintained across steam rise end points. On the other hand, the cooling water inlet and outlet temperatures across the condenser, were recorded as $16^{\circ} \mathrm{C}$ and $23^{\circ} \mathrm{C}$ respectively. This also give a temperature difference of $7^{\circ} \mathrm{C}$, same as that across steam riser. However, some of the power of $0.868 \mathrm{~kW}$ is lost to the brine which is rejected at $33^{\circ} \mathrm{C}$ after heating from $23^{\circ} \mathrm{C}$. It must be noted that, although the main heat input is coming from the hot water, but the media that is being used 
to exchange heat with the incoming feed is the heat supplying vapors which are generated in the steam rise at $40^{\circ} \mathrm{C}$. On the other hand, the produced vapors in the condenser are at the temperature of $32^{\circ} \mathrm{C}$, which lose around $12^{\circ} \mathrm{C}$ temperature in the condenser as the distillate output has temperature of $20^{\circ} \mathrm{C}$.

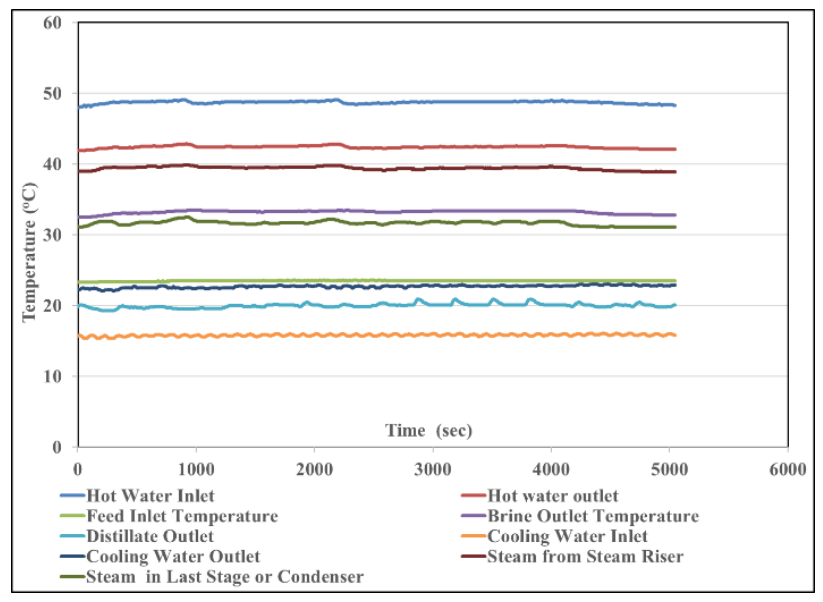

(a)

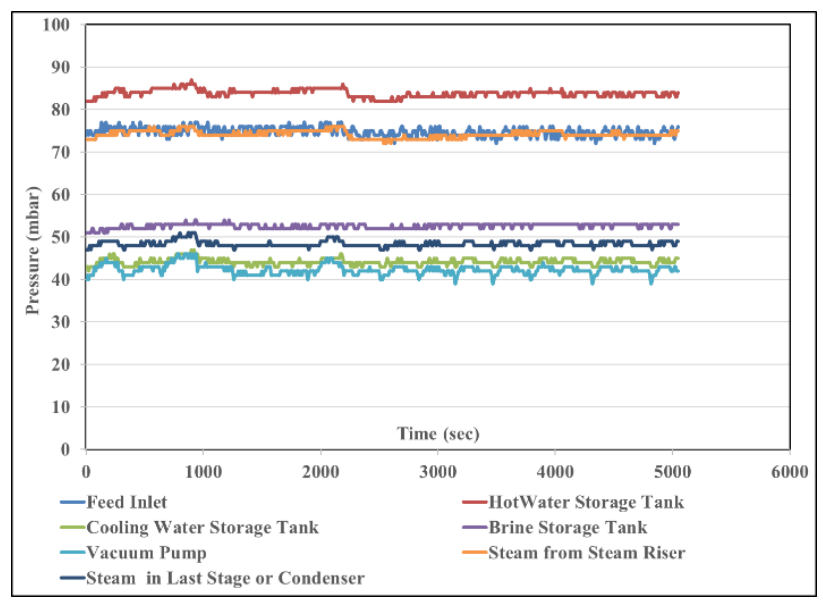

(c)

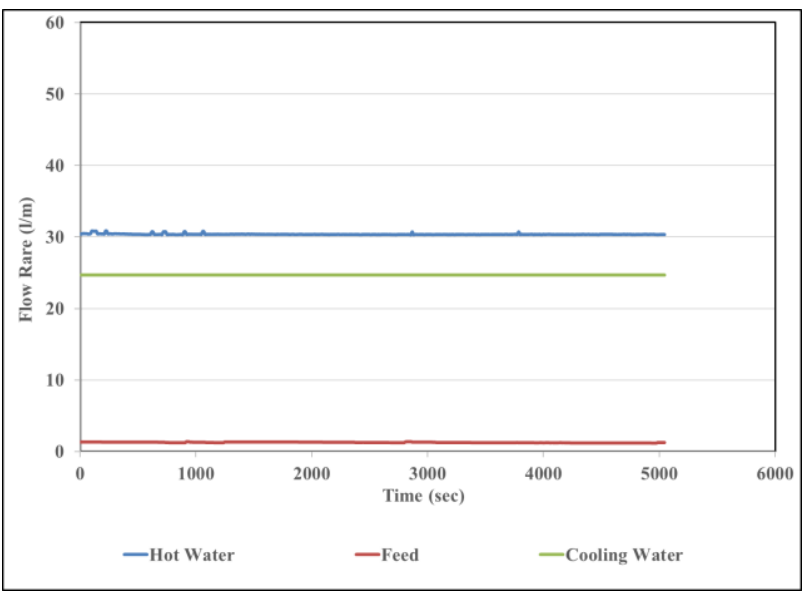

(b)

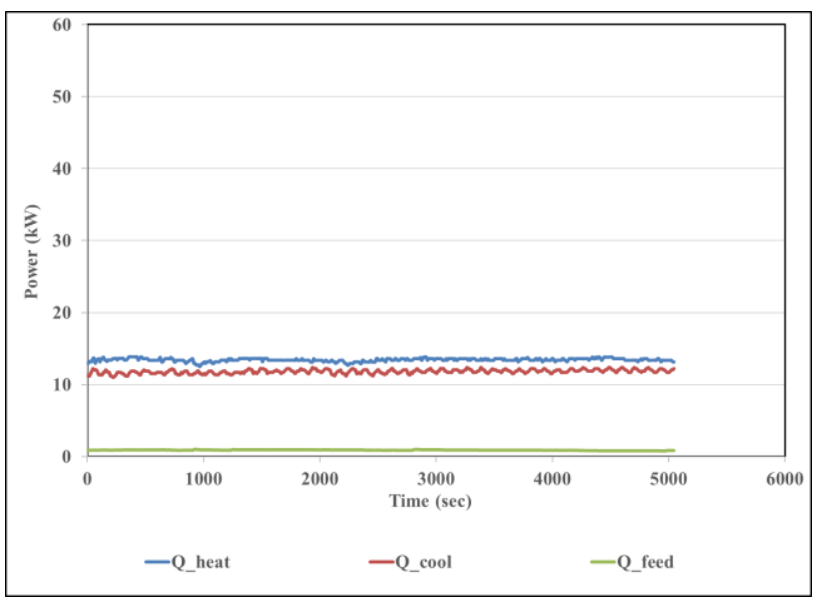

(d)

Figure 4: Single Effect VMD System Performance (a) Temperature Distribution (b) Flow Rate (c) Pressure Profile (d) Power Profile

Figure 4(c) shows the pressure profiles at each component of the VMD system. The lowest pressure point is the vacuum pump, which is the driving force for the vapor flow. On the other hand, the highest pressure point is the hot water storage tank. This pressure increase dictates the distance or position of the system component from the lowest pressure point. The pressure drop between each of the component corresponds to the resistance for vapor flow. As the vacuum pump is pulling the vacuum from the condenser side, therefore, the cooling water circuit has the lowest pressure, slightly above the vacuum pump pressure. Then, there is a slight increase in the pressure of condensing steam in the condenser, due to vapor presence and flow. On the other hand, the brine tank also have slightly higher pressure than the condensing steam in the condenser, which is 
because of the fact that the brine and the last stage steam are separated by hydrophobic membrane which has created this pressure difference. After brine tank, there is a quite significant increase in the pressure as now it represents the other end of the VMD modules.

Moreover, the power supplied and rejected by the fluid flows is shown in Fig. 4(d). It can be seen that about $13.2-13.5 \mathrm{~kW}$ of power is supplied by the hot water to the VMD system, out of which about $11.7-12.2 \mathrm{~kW}$ is rejected in the condenser and $0.8-0.9 \mathrm{~kW}$ is rejected in form of brine, indicating a large amount of heat loss to the ambient.

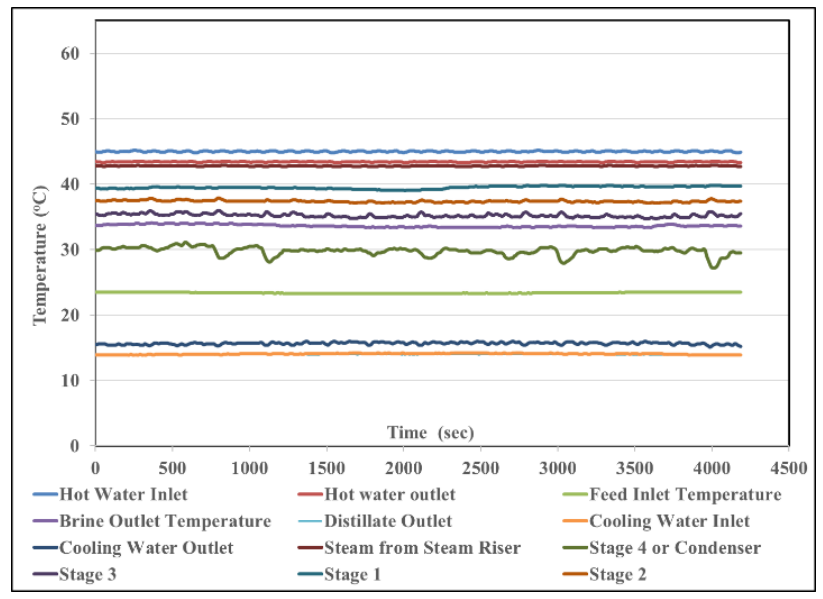

(a)

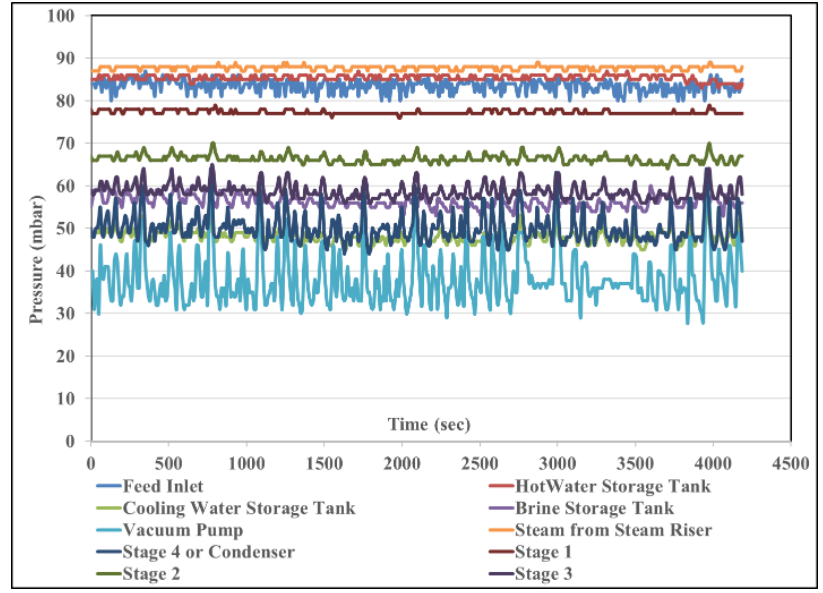

(c)

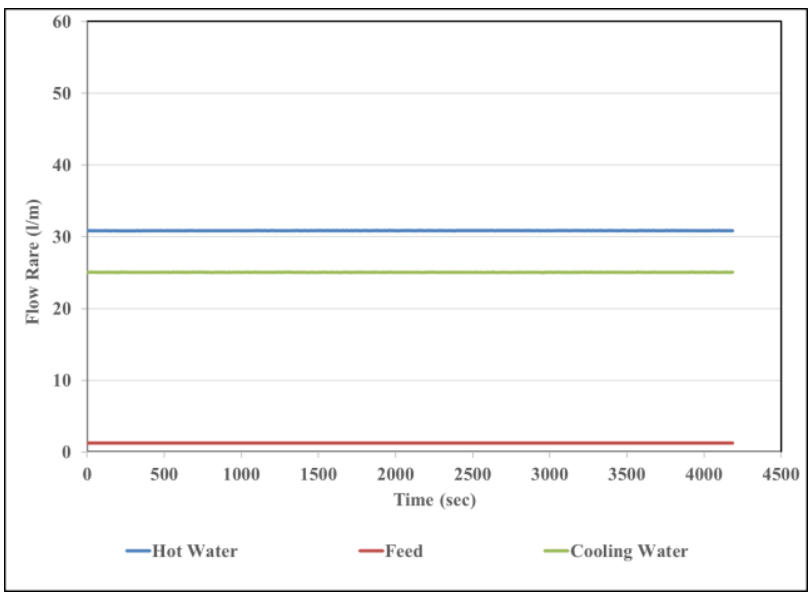

(b)

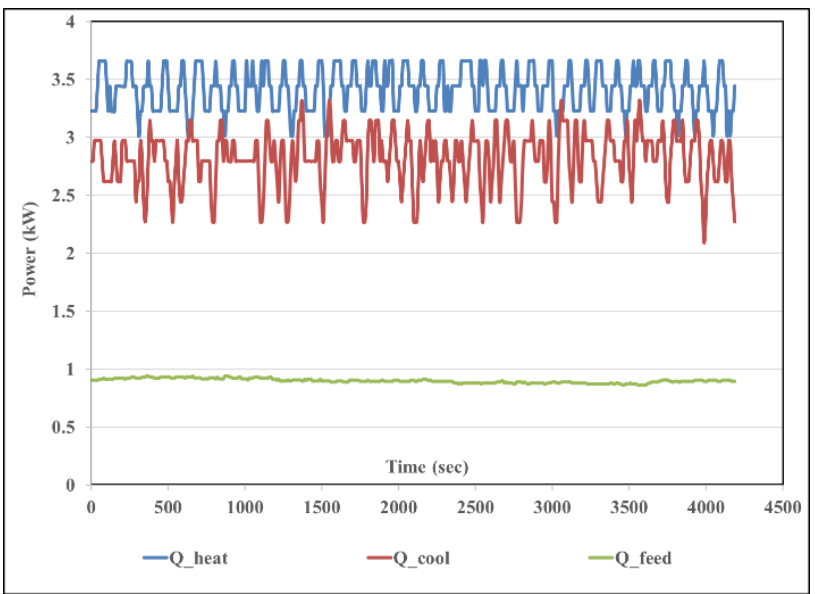

(d)

Figure 5: Multi-Effect VMD System Performance (a) Temperature Distribution (b) Flow Rate (c) Pressure Profile (d) Power Profile

Figure 5(a) shows the temperature profile of different components of the VMD system under multi-effect arrangement, with hot water inlet set temperature of $45^{\circ} \mathrm{C}$. However, feed inlet and cooling water inlet temperatures are same as the previous experiment. From the temperature profile, it can be seen that the brine and distillate outlet temperature are recorded as $33^{\circ} \mathrm{C}$ and $16^{\circ} \mathrm{C}$, respectively. The cooling water inlet and outlet temperatures across the condenser were recorded 
as $16^{\circ} \mathrm{C}$ and $18^{\circ} \mathrm{C}$ respectively, with temperature difference same as that of across steam riser i.e. $2^{\circ} \mathrm{C}$. However, there is about $2.0^{\circ} \mathrm{C}$ temperature difference between each stage, till brine discharge at $33^{\circ} \mathrm{C}$.

Figure 5(c) shows the pressure profiles at each component of the multi-effect VMD process. The distribution of pressure across each component is same as explained above. However, there is about 8-10mbar pressure difference between each stage, corresponding to the saturation pressure of the feed temperature. This pressure gradient helps in the vapor flow through the stages. The interesting comparison of performance between single effect and multi-effect arrangements is the power consumption. It can be seen that about $3.4-3.6 \mathrm{~kW}$ of the power is supplied to the VMD system in multi-effect configuration and out of which, about $2.4 \mathrm{~kW}$ is rejected in the condenser. However, as compared to the power consumption of $13.5 \mathrm{~kW}$ for single effect configuration, the low power consumption of multi-effect configuration is because of the fact that the heat is only supplied to single stage, while it is recovered in other stages.

It must be noted that some of the fluctuating trends in the performance is due to high sensitivity of the sensors, especially for pressure sensors, or due to small scale of the graphs. The pressure fluctuations are higher for lower stages at lower pressure as the vacuum pump operates cyclic when system reaches steady state. Currently, the system does not have the facility to calculate the power consumed by the auxiliary equipment e.g. circulation and vacuum pumps. It must be noted that this is a test bench system to study the performance of the VMD configuration. The power consumption of auxiliary equipment may seems to be large here but in actual industrial facility, it counts very less.

The performance profiles discussed above, help to analyze the system at component level but at certain temperature. The other main objective of this study is to analyze the system production against different feed temperatures as the main application of the VMD system here is the water production. It must be noted that the single layer of each VMD module has contact area of $0.47 \mathrm{~m}$ $\mathrm{x} 0.33 \mathrm{~m}$. With 11 layer per stage, the total contact area for one VMD module is $1.7061 \mathrm{~m}^{2}$. Figure 6 shows the variation of the distillate production for VMD system against different hot water inlet temperatures with feed flow rate of 1.24LPM as it is the optimum flow rate of feed for the system, mentioned by the manufacturer. In case of single effect, the production graph shows an exponential variation against the hot water inlet temperature, with anchor point at $35^{\circ} \mathrm{C}$. It can be seen that above $40^{\circ} \mathrm{C}$, the production graph has increasing slop. On the other hand, the slope of the graph is also increasing below $30^{\circ} \mathrm{C}$. The slope of the production graph is almost straight from $30^{\circ} \mathrm{C}$ to $40^{\circ} \mathrm{C}$, which is because of the fact that this is considered as the dead state as it matches with the ambient conditions. The only reason to test the VMD at temperature lower than the ambient temperature, is to see the system performance at low temperature as the feed was available at as low as $23^{\circ} \mathrm{C}$. This result is only suitable to analyze the system performance when feed is available at very low temperature, which is mostly possible in case of the hybrid systems and there is a need for further recovery from the system. However, in most of the regions, the feed temperature is 
mostly above $30^{\circ} \mathrm{C}$, same as most of the ambient temperatures and the recommended heat source temperature is way above $40^{\circ} \mathrm{C}$, for efficient operation.

Similarly, the multi-effect configuration also shows an exponential variation against the hot water inlet temperature, with saturation point as $45^{\circ} \mathrm{C}$. It can be seen that above $40^{\circ} \mathrm{C}$, the production is increasing sharply and becomes saturated for temperature over $45^{\circ} \mathrm{C}$. This shows that the heat transfer area is not enough to have higher production at flow rate of 1.24LPM and temperature higher than $45^{\circ} \mathrm{C}$. As compared to the single-effect, the multi-effect configuration showed higher distillate production and recovery ratio for temperature higher than $43^{\circ} \mathrm{C}$. This shows that the area of VMD modules is optimized for temperature range of $43-46^{\circ} \mathrm{C}$ with $1.24 \mathrm{LPM}$ feed per module. For high temperature operation, either feed flow rate is need to be decreased for better contact time or contact area is needed to be increased.

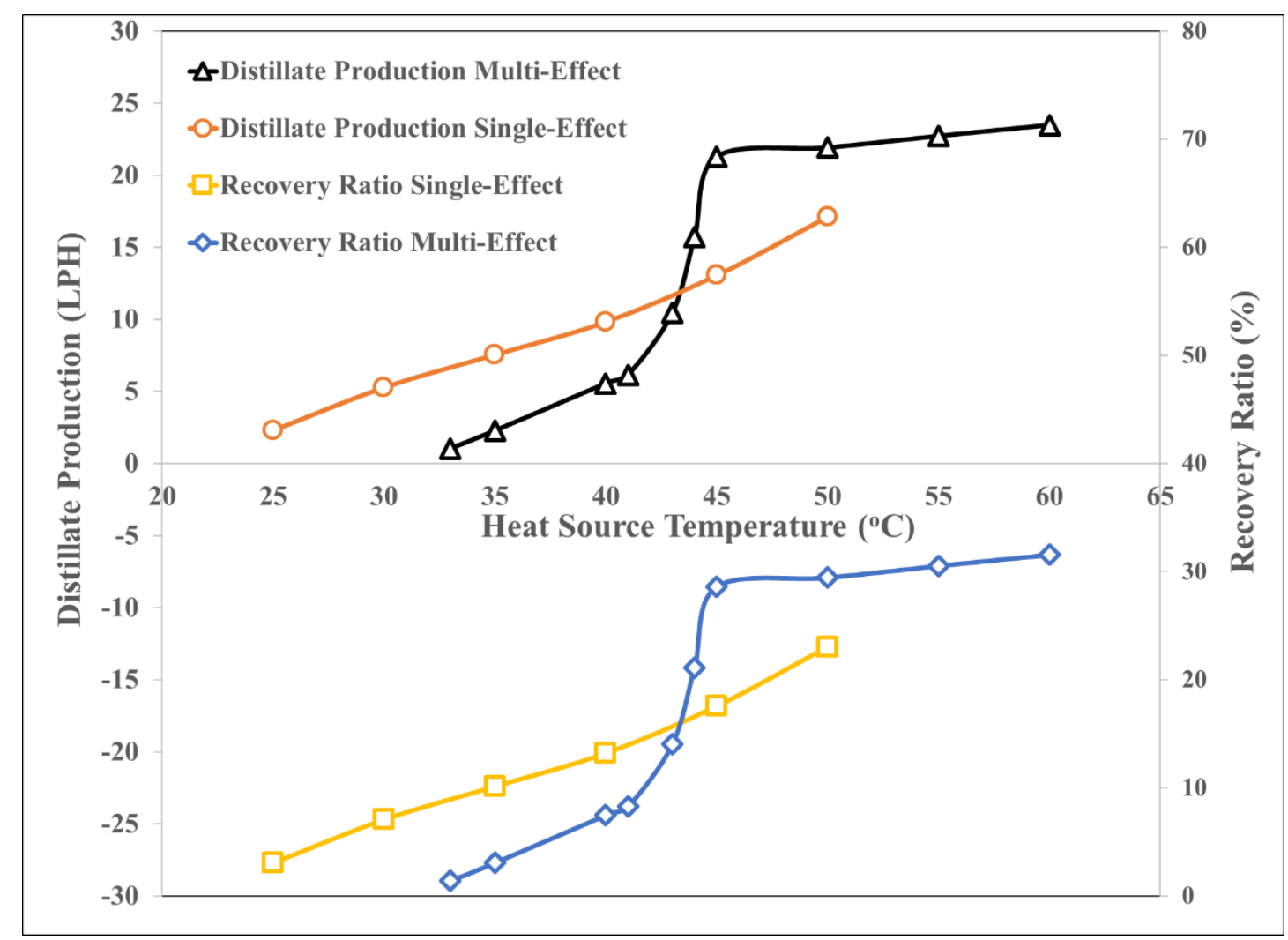

Figure 6: VMD Water Production and Recovery Ratio against Heat Source Temperature

\section{Conclusion}

A detailed performance analysis of vacuum membrane distillation (VMD) is carried out with 4stages working in single effect and multi-effect configurations. The performance of the system is investigated for different feed flow temperatures. The single-effect configuration showed higher energy input of $13.5 \mathrm{~kW}$ as energy was supplied to 4 modules simultaneously. However, in multieffect configuration, significantly lower energy of $3.4 \mathrm{~kW}$ was consumed, which was only in the 
first stage. This heat was further utilized as internal heat recovery in subsequent stages. The singleeffect configuration showed exponential trend of distillate production against feed temperatures. On the other hand, the multi-effect configuration showed higher distillate production but with saturation point at $45^{\circ} \mathrm{C}$. In case of single-effect configuration, higher distillate production was observed at lower feed temperature. In conclusion, the system showed better performance in multieffect configuration with less energy consumption and higher recovery ratio.

\section{Acknowledgement}

This study was supported by King Abdullah University of Science and Technology. All of the figure in this paper are reproduced with the permission of authors of WDRC CCF Grant report of period 2016-2018 [34].

\section{References}

[1] Shahzad MW, Burhan M, Ng KC. Energy Storage \& Desalination. International Journal of Computational Physics Series 2018, 1(2), 52-60.

[2] Mekonnen MM, Hoekstra AY. Four billion people facing severe water scarcity. Science advances. 2016, 2(2):e, 1500323.

[3] Burhan M, Chua KJ, Ng KC. Sunlight to hydrogen conversion: Design optimization and energy management of concentrated photovoltaic (CPV-Hydrogen) system using micro genetic algorithm. Energy 2016, 99, 115-28.

[4] Burhan M, Shahzad MW, Ng KC. Long-term performance potential of concentrated photovoltaic (CPV) systems. Energy Conversion and Management 2017, 148, 90-9.

[5] Darwish MA, Abdulrahim HK, Mohieldeen Y. Qatar and GCC water security. Desalination and Water Treatment 2015, 55(9), 2302-25.

[6] International Energy Outlook 2016 with Projections to 2040. A report by U.S. Energy Information Administration (EIA), 2016.

[7] Hamed OA, Al-Sofi MA, Imam M, Mustafa GM, Mardouf KB, Al-Washmi H. Thermal performance of multi-stage flash distillation plants in Saudi Arabia. Desalination 2000, 128(3), 28192.

[8] Al-Sahlawi MA. Seawater desalination in Saudi Arabia: economic review and demand projections. Desalination 1999, 123(2-3), 143-7.

[9] Oh SJ, Burhan M, Ng KC, Kim Y, Chun W. Development and performance analysis of a two-axis solar tracker for concentrated photovoltaics. International Journal of Energy Research 2015, 39(7), 965-76.

[10] Burhan M, Oh SJ, Chua KJ, Ng KC. Solar to hydrogen: Compact and cost effective CPV field for rooftop operation and hydrogen production. Applied energy 2017, 194, 255-66. 
[11] Hilton I, Kerr O. The Paris Agreement: China's 'New Normal'role in international climate negotiations. Climate Policy 2017, 17(1), 48-58.

[12] Boudries R. Analysis of solar hydrogen production in Algeria: Case of an electrolyzerconcentrating photovoltaic system. International Journal of Hydrogen Energy 2013, 38(26), 1150711518.

[13] Burhan $\mathrm{M}$, Chua $\mathrm{KJ}, \mathrm{Ng} \mathrm{KC}$. Long term hydrogen production potential of concentrated photovoltaic (CPV) system in tropical weather of Singapore. International Journal of Hydrogen Energy 2016, 41(38), 16729-42.

[14] Ng KC, Burhan M, Shahzad MW, Ismail AB. A Universal Isotherm Model to Capture Adsorption Uptake and Energy Distribution of Porous Heterogeneous Surface. Scientific Reports 2017, 7(1), 10634.

[15] Burhan M, Shahzad MW, Ng KC. Hydrogen at the rooftop: Compact CPV-hydrogen system to convert sunlight to hydrogen. Applied Thermal Engineering 2018, 132, 154-64.

[16] Burhan M, Oh SJ, Chua KJ, Ng KC. Double lens collimator solar feedback sensor and master slave configuration: Development of compact and low cost two axis solar tracking system for CPV 4applications. Solar Energy 2016, 137, 352-63.

[17] Burhan M, Chua KJ, Ng KC. Simulation and development of a multi-leg homogeniser concentrating assembly for concentrated photovoltaic (CPV) system with electrical rating analysis. Energy conversion and management 2016, 116, 58-71.

[18] Burhan M, Shahzad MW, Ng KC. Sustainable Cooling with Hybrid Concentrated Photovoltaic Thermal (CPVT) System and Hydrogen Energy Storage. International Journal of Computational Physics Series 2018, 1(2), 40-51.

[19] Burhan M, Shahzad MW, Ng KC. Concentrated Photovoltaic (CPV): Hydrogen Design Methodology and Optimization. In Advances In Hydrogen Generation Technologies 2018. IntechOpen. DOI: 10.5772/intechopen.78055

[20] Shahzad MW, Burhan M, Son HS, Oh SJ, Ng KC. Desalination processes evaluation at common platform: A universal performance ratio (UPR) method. Applied Thermal Engineering 2018, 134, 627.

[21] Burhan M, Shahzad MW, Ng KC. Development of performance model and optimization strategy for standalone operation of CPV-hydrogen system utilizing multi-junction solar cell. International Journal of Hydrogen Energy 2017, 42(43), 26789-803.

[22] Vidal-Amaro JJ, Østergaard PA, Sheinbaum-Pardo C. Optimal energy mix for transitioning from fossil fuels to renewable energy sources-The case of the Mexican electricity system. Applied Energy 2015, 150, 80-96.

[23] Subramani A, Jacangelo JG. Emerging desalination technologies for water treatment: a critical review. Water research 2015, 75, 164-87.

[24] Burhan M, Shahzad MW, Oh SJ, Ng KC. A pathway for sustainable conversion of sunlight to hydrogen using proposed compact CPV system. Energy Conversion and Management 2018, 165, 102-12. 
[25] Chandrashekara M, Yadav A. Water desalination system using solar heat: a review. Renewable and Sustainable Energy Reviews 2017, 67, 1308-30.

[26] Shahzad MW, Ybyraiymkul D, Burhan M, Ng KC. Renewable Energy-Driven Desalination Hybrids for Sustainability. In Desalination and Water Treatment 2018. IntechOpen. DOI: 10.5772/intechopen.77019

[27] Al-Karaghouli A, Kazmerski LL. Energy consumption and water production cost of conventional and renewable-energy-powered desalination processes. Renewable and Sustainable Energy Reviews 2013, 24, 343-56.

[28] Borsani R, Rebagliati S. Fundamentals and costing of MSF desalination plants and comparison with other technologies. Desalination 2005, 182(1-3), 29-37.

[29] Patel VU, Multani S. A Review on Seawater Desalination Technology and Concentrating Solar Power.

[30] Miller S, Shemer H, Semiat R. Energy and environmental issues in desalination. Desalination 2015, 366, 2-8.

[31] Cai C, Feng H, Chen L, Wu Z, Xie Z. Constructal design of a shell-and-tube evaporator with ammonia-water working fluid. International Journal of Heat and Mass Transfer 2019, 135, 541-7.

[32] Shahzad MW, Burhan M, Ng KC. Pushing desalination recovery to the maximum limit: membrane and thermal processes integration. Desalination 2017, 416, 54-64.

[33] Henthorne L, Boysen B. State-of-the-art of reverse osmosis desalination pretreatment. Desalination 2015, 356, 129-39.

[34] WDRC (KAUST) CCF Grant report of period 2016-2018 (muhammad.burhan@kaust.edu.sa). 